Research Article

\title{
Incorporating Variability in Lean Manufacturing: A Fuzzy Value Stream Mapping Approach
}

\author{
Qingqi Liu $\mathbb{C}^{1}$ and Hualong Yang $\mathbb{D}^{1,2}$ \\ ${ }^{1}$ College of Transportation Engineering, Dalian Maritime University, Dalian, China \\ ${ }^{2}$ Logistics Research Institute, Dalian Maritime University, Dalian, China \\ Correspondence should be addressed to Hualong Yang; hlyang@dlmu.edu.cn
}

Received 3 June 2020; Accepted 23 November 2020; Published 14 December 2020

Academic Editor: Jean Jacques Loiseau

Copyright (c) 2020 Qingqi Liu and Hualong Yang. This is an open access article distributed under the Creative Commons Attribution License, which permits unrestricted use, distribution, and reproduction in any medium, provided the original work is properly cited.

\begin{abstract}
In this paper, value stream mapping (VSM) is integrated with fuzzy set theory to incorporate variability and uncertainty in the lean production system. VSM is one of the primary analytical tools for identifying waste and optimizing a production line. However, the standard VSM fails to consider the variability in manufacturing environments, which is, in fact, one of the root causes of waste. Therefore, this article proposes fuzzy VSM to overcome this weakness. Two alternative forms of fuzzy numbers, triangular fuzzy numbers (TFNs) and normal fuzzy numbers (NFNs), are applied, respectively, to depict time intervals, inventories, and other operating variables in VSM. An industrial case for assessing the validity of the proposed approaches is presented. Both approaches make it possible to incorporate and analyze variability in VSM and can be easily applied to industrial cases, as they only require basic algebraic operations. The obtained results are compared and the choice between TFNs and NFNs is discussed accordingly. A triangular fuzzy VSM tends to overestimate the variability of the process in complex production environment with complicated operational processes. However, it permits a more accurate description of variation in the environment where the optimistic and pessimistic values have very different variations from the core.
\end{abstract}

\section{Introduction}

Lean manufacturing, originated from the Toyota Production System, has been receiving great attention from researchers and practitioners since its production [1]. The lean production system has been widely applied in manufacturing industry worldwide and is considered as one of the most effective approaches in improving operational efficiency [2-4]. In general, the analysis of the product value stream is implemented as the first step toward leanness, as it helps in identifying the areas where the improvement efforts should be concentrated [5]. Value stream mapping (VSM) is a visual tool that facilitates the process of the lean production system through identifying value-added activities and eliminating wastes [6]. It can be described as "a graphical tool used to map the as-is situation of the organization, to identify opportunities for waste elimination, and to decide the improvements to be implemented to eliminate the waste" [7], and it has found its way into various industries and domains as one of the key lean tools $[8,9]$.

However, the conventional VSM methodology is unable to give a real vision of the variability problems concerning the production process analyzed. Indeed, variability is one of the important factors influencing the cycle time of each stage and the work-in-process (WIP) between adjacent processes [10]. It affects the queueing time and causes congestion and uncertainty in input rates and processing times. Such variability originates from various aspects, which include but are not limited to the characteristics of the product (and WIP) itself, the workforce, the equipment, and the environment, of the value stream. Therefore, it is always difficult to obtain deterministic values when collecting data associated with times, inventories, and other operating variables [11]. Moreover, the uncertainty in data and their intrinsic variability acts as one of the root causes of waste [12] and is a significant noise factor in terms of processes, inputs, outputs, 
random breakdowns, and random setup times for a pull system. Considering these issues, the lack of consideration of real variability in the value stream is one of the main drawbacks of VSM. To overcome this weakness, this paper proposes a fuzzy VSM method to incorporate variability in value stream analysis and improvement. The same issue also has been studied by Braglia et al. [11] and Seyedhosseini et al. [13]. Braglia et al. [11] proposed two alternative approaches based on statistics and fuzzy algebra, respectively. Both methods were designed to support practitioners and can be easily employed in industrial applications. Seyedhosseini et al. [13] applied fuzzy set theory to map the value stream and to determine the best future-state VSM. However, these two studies both simply use triangular fuzzy numbers to describe values in VSM without considering and comparing the appropriateness and accuracy of different fuzzy expressions in different production environments. The current study is conducted to fill the research gap. This paper adopts two forms of fuzzy numbers, triangular fuzzy number (TFN) and normal fuzzy number (NFN), respectively, to describe time intervals, inventories, and other operating variables in VSMs. Moreover, two alternative ranking methods of fuzzy numbers, namely, modified coefficient of variation $(\mathrm{CV})$ and centroid point method, are proposed to determine the ideal fuzzy VSM. Modified CV index enables decision makers to assign different weight on the mean value and standard deviation of fuzzy numbers. The centroid point method can be easily performed in the comparison of TFNs but encounters computational difficulties in the ranking of NFNs. In order to accelerate the computation, this paper proposes a novel method to determine the approximate centroid point of NFNs.

The remainder of this paper is structured as follows. A review of literature on existing and related work is presented first, followed by the presentation of fuzzy VSM in two forms. Next, the proposed fuzzy VSM approach is demonstrated through an industrial application, followed by the discussion of the choice from two forms of fuzzy VSM according to the case results. Finally, conclusions and future research prospects are presented at the end of the paper.

\section{Literature Review on VSM}

The core of VSM consists of the definition of a current-state VSM and a future-state VSM [14, 15]. A graphical presentation of both materials and information flow in the current system is defined as a current-state VSM, which has a timeline showing the average time spent by an item at each stage of the production process in both value-added and non-value-added activities [16]. Accordingly, the total production lead time (TPLT) can be obtained by summing all the times reported on the timeline [17]. Furthermore, this permits to compute the efficiency $\eta$ of the production line as the ratio of the total value-added time (TVAT) with respect to the TPLT (i.e., $\eta=$ TVAT/TPLT), which serves as one of the main criteria in evaluating the leanness of the supply chain $[5,18]$. With reference to current-state VSM, an analyst identifies and measures the waste generated from incapacity, inefficiency, and the unreliability of information, time, money, space, people, machines, materials, and manufacturing tools during the management of processing within an organization, and improvement initiatives are created accordingly [7]. A future-state VSM indicating modifications and continuous improvement plans is then developed for the system [19].

Compared to other mapping techniques, VSM has some specific features, making VSM important and unique for lean manufacturing. For instance, VSM not only manages the manufacturing processes but also optimizes the whole system by creating a holistic view of it $[13,20]$. VSM is a door-to-door demonstration for visualizing a production process at the plant level rather than the single-process level and illustrating the flow of materials and information in the entire supply chain rather than for separate manufacturing plants [21]. Thus, it includes information related to production times, as well as to inventory levels, and offers a reflection of systemic vision maintaining local details of process by diagrammatically linking material flow, information flow, and timeline [6]. Moreover, by using operating parameters such as Takt time, which determines the production rate at which each processing stage in the manufacturing system should operate, VSM links product planning and demand forecasts to production scheduling and flow-shop control. Through visualized mapping, VSM successfully forms a blueprint for lean implementation and can be integrated into various qualitative and quantitative analyses-based tools to refine and redesign strategic improvements [22].

Due to its effectiveness and advantages in promoting lean manufacturing, the implementation of VSM has been studied by many scholars. Some of the studies lead to a further improvement in the VSM technique. Abbas et al. [23] proposed an innovative mapping technique named value network mapping (VNM) obtained from an integration of production flow analysis and simplification toolkit into VSM. The authors show that VNM supports lean manufacturing through the creation of U-shaped cells and improvement of material handling methodologies. Braglia et al. [24] developed a step-by-step procedure named improved value stream mapping that makes it possible to apply VSM to products characterized by complex bills of materials. The basic idea of the method is using a temporized bill of material to identify the critical production path. Then, all possible sharing with secondary paths are considered as possible constraints to make improvements to the critical path. McDonald et al. [25] and Lian and Landeghem [26] pointed out that traditional VSM lacks the capability for the rapid development and evaluation of multiple what-if analyses required to prioritize different alternatives. To overcome this lack, both papers suggested combining VSM with discrete-event simulation to define the basic parameters for the FSM (i.e., number of kanbans, pitch increments, micromix, etc.) and to assess the effects of these parameters on the performance of the system. In terms of the application environment, although lean manufacturing originates from the automobile sector, various studies have shown mixed results in the implementation of lean manufacturing in different industry sectors. For instance, Pavnaskar and Gershenson [27] identified the main differences and 
similarities between a productive and an engineering process. Their analysis was used to accommodate VSM for engineering processes. Zokaei and Simons [28] introduced lean thinking to the red meat industry. Lean production techniques (principally Takt time and standard operations) were proven to make significant contributions to all stages of the red meat value chain, resulting in a $2 \%-3 \%$ potential cost savings for each actor in the chain [28]. Jimenez et al. [29] elaborated on the application of the lean concept to wine processing in an environment of continuous production. The authors used VSM as the main tool to identify process wastes, developed present and future maps with plans for improvement, and found that VSM highlighted areas of improvement [29]. Also, the application of VSM in the pharmaceutical industries was examined by Chowdary and George [30] and several opportunities were explored to reduce lead times, cycle times, and WIP inventory levels.

\section{Fuzzy VSM}

To handle the variability of value stream parameters in a computational way, fuzzy set theory is applied to transform the uncertainties into fuzzy numbers [31]. A fuzzy set can be viewed as a subset from the real number set that represents uncertain values [32]. Zadeh [33] defines a fuzzy set as a class of objects having a range of degrees of membership. Such a set is characterized by a membership function $\mu(x)$ that assigns each object class a membership degree between zero and one. The degree indicates whether an object or element is located wholly inside, wholly outside, or partially inside and outside the set. The membership of this set is graduated and not related to a probability distribution [33]. This paper applies TFNs and NFNs, respectively, to describe the variability in VSM.

3.1. TFN-Based VSM. The first approach is the use of TFNs to describe the time intervals spent by an item for each stage of the production process. The use of TFNs appears to be compatible with the aim of VSM, since they offer a good trade-off between computational costs and accuracy in the final ranking. A generic TFN $\tilde{A}$ is defined by an ordered quartet $\tilde{A}=(\mathrm{a}, \mathrm{b}, \mathrm{c})$, where a represents the lower bound and $c$ represents the upper bound, respectively. c-a suggests the fuzzy degree of $\tilde{A}$ : the larger the value of $\mathrm{c}$-a, the higher is the degree of fuzziness. TFN $\tilde{A}$ degenerates into a real number in the case of $a=b=c$. The interval $[a, c]$ is denoted as the support of $\tilde{A}$. The membership function $\mu \tilde{A}(x)$ is the bilinear relation given in the following relation:

$$
\mu \tilde{\mathrm{A}}(x)= \begin{cases}0, & x \leq a, \\ \frac{x-a}{b-a}, & a<x \leq b, \\ \frac{c-x}{c-b}, & b<x \leq c, \\ 0, & x>c .\end{cases}
$$

To describe the processing and waiting times with the appropriate TFNs, data collection should be carefully conducted to acquire the sample data. To determine the values of $\mathrm{a}, \mathrm{b}$, and $\mathrm{c}$, this study introduces parameter $\alpha$, which is similar to that proposed by Rommelfanger [34]:

(i) $\alpha=1: \mu(x)=1$ means that value $x$ certainly belongs to the set of possible values.

(ii) $\alpha=\lambda: \mu(x)>\lambda$ means that value $\lambda$ has a chance of $\mu(x)>\lambda$ belonging to the set of possible values.

Therefore, the value of $b$ is set to the mean of the sample data at an $\alpha$-cut $\alpha_{1}=1$. The minimum and maximum values of the sample correspond to an $\alpha$-cut $\alpha_{2}=0.1$, rather than to 0 , in order to incorporate other possible extreme values that fail to be captured by observation. Accordingly:

$$
\begin{aligned}
& a=\frac{(\min (\text { sample })-0.1 b)}{0.9}, \\
& b=\mu(\text { sample }), \\
& c=\frac{(\max (\text { sample })-0.1 b)}{0.9} .
\end{aligned}
$$

If it is impossible to collect real data intervals, for instance, in the calculation of future-state performance, the process staff will be asked to provide the most likely estimate at an $\alpha$-cut $\alpha_{1}=1$, as well as the optimistic and pessimistic estimates at an $\alpha$-cut $\alpha_{2}=0.1$. The meanings of these three estimates are as follows:

(i) The most likely estimate at an $\alpha$-cut $\alpha_{1}=1$ represents a value that definitely belongs to the set of duration estimations.

(ii) The optimistic and pessimistic estimates at $\alpha$-cut $\alpha_{2}=0.1$ define an interval in which each value has a probability above 0.1 of belonging to the set of duration estimations.

In this way, $\mathrm{b}$ is the most likely estimated duration, and the values of a and $c$ can be calculated using the membership function:

$$
\begin{aligned}
& a=\frac{\text { (optimistic estimate }-0.1 b)}{0.9}, \\
& c=\frac{\text { (pessimistic estimate }-0.1 b \text { ) }}{0.9} .
\end{aligned}
$$

3.2. NFN-Based VSM. The second form of fuzzy number applied is NFN. The membership function of an NFN can be expressed as

$$
\mu \tilde{\mathrm{A}}(x)=e^{-\left((x-\mu)^{2} / 2 \sigma^{2}\right)}, \quad \sigma>0 .
$$

As a result, $\tilde{A}$ can be uniquely identified by $\mu$ and $\sigma$ and then expressed as $\tilde{A}=(\mu, \sigma) . \tilde{A}$, as a fuzzy number, is capable of objectively describing the actual time intervals spent by an item for each stage of the productive process, which is vulnerable to multiple influencing factors. For two NTNs 
$\tilde{A}_{1}=\left(\mu_{1}, \sigma_{1}\right)$ and $\tilde{A}_{2}=\left(\mu_{2}, \sigma_{2}\right)$ (see Appendix A for the proof process):

$$
\begin{aligned}
& \widetilde{A}_{1}+\widetilde{A}_{2}=\left(\mu_{1}+\mu_{2}, \sigma_{1}+\sigma_{2}\right), \\
& \widetilde{A}_{1}-\widetilde{A}_{2}=\left(\mu_{1}-\mu_{2}, \sigma_{1}-\sigma_{2}\right) .
\end{aligned}
$$

3.3. Ranking Fuzzy VSMs. This paper suggests two alternative approaches to compare or rank the future-state VSMs in terms of performance criteria such as production line efficiency (measured by $\eta=$ TVAT/TPLT), both of which offer a good compromise between the computational complexity and the robustness of the final result.

3.3.1. Modified CV Method. Cheng et al. [35] proposed the concept of CV index, defined as $\sigma / \mu$, where $\sigma$ and $\mu$ refer to the standard deviation and the mean, respectively, of fuzzy numbers. The fuzzy number with smaller CV suggests a lower degree of dispersion and gets a higher ranking accordingly. The standard deviation and mean value are given the same degree of significance in this method, while decision makers might prefer different priorities of the indicators in practical application. Therefore, this paper proposes modified CV index to solve the problem.

$$
\text { modified CV }=\frac{\sigma^{\alpha}}{\mu^{1-\alpha}}, \quad \alpha \in[0,1] .
$$

$\alpha>0.5$ suggests a higher importance of standard deviation; $\alpha<0.5$ suggests a higher importance of mean value; and $\alpha=0.5$ suggests an equal importance of standard deviation and mean value.

For TFN $\tilde{A}=(\mathrm{a}, \mathrm{b}, \mathrm{c}), \mu$ and $\sigma$ can be expressed as [36]

$$
\begin{aligned}
& \mu=\frac{a+b+c}{3}, \\
& \sigma=\sqrt{\frac{a^{2}+b^{2}+c^{2}-a b-a c-b c}{18} .}
\end{aligned}
$$

For NTN $\tilde{A}=(\mu, \sigma), \mu$ and $\sigma$ are identified as $\tilde{A}$ suggests.

Accordingly, the value of modified CV can be easily obtained and the fuzzy number with smaller modified CV is ranked higher. This method provides an efficient approach in ranking fuzzy numbers, yet it fails in the ranking of fuzzy numbers with different $\mu$ and $\sigma$ values but same $\sigma / \mu$ value if equal importance is given to standard deviation and mean value. For instance, NTN $\tilde{A}_{1}=(2,1)$ and NTN $\tilde{A}_{2}=(4,2)$ have same value of modified $\mathrm{CV}$ when $\alpha=0.5$. Consequently, an alternative ranking procedure is described in the following section.

3.3.2. Centroid Point Method. The centroid point of a fuzzy number corresponds to an $\bar{x}$ value on the horizontal axis and a $\bar{y}$ value on the vertical axis. The centroid point method uses distance between centroid and original points (i.e., $R(A)=\sqrt{\bar{x}^{2}+\bar{y}^{2}}$ ) as the indicator of fuzzy number ranking: for larger-the-better parameters, the fuzzy number with larger value of $R(A)$ is ranked higher; for smaller-the-better parameters, the fuzzy number with lower value of $R(A)$ is ranked higher. It should be noted that although this method has been criticized by scholars for its deficiency in dealing with negative fuzzy numbers [37], it works well in the situation described in this research because parameters in VSM, such as time intervals and WIP volumes, cannot be negative values.

For fuzzy number TFN $\tilde{A}=(\mathrm{a}, \mathrm{b}, \mathrm{c})$, the centroid point $(\bar{x}, \bar{y})$ is $[38]$

$$
\begin{aligned}
& \bar{x}=\frac{a+b+c}{3}, \\
& \bar{y}=\frac{1}{3} .
\end{aligned}
$$

For NTN $\tilde{A}=(\mu, \sigma)$, the calculation of centroid point is complicated and time consuming; hence, this paper proposes a novel method to determine the approximate centroid point efficiently. The main idea is to replace the membership function of NTNs by linear function approximation. The membership function of an NTN $\tilde{A}=(\mu, \sigma)$ is described in equation (6) and illustrated as Figure 1.

The concavity and convexity of the function change in the points where the second derivative of $\mu \tilde{\mathrm{A}}(x)$ equals 0 (i.e., $\mu \tilde{\mathrm{A}}(x)^{\prime \prime}=0$ ); accordingly, the inflection points are $(\mu-\sigma,(1 / \sqrt{e}))$ and $(\mu+\sigma,(1 / \sqrt{e}))$. We draw a tangent to the normal distribution curve through $(\mu-\sigma,(1 / \sqrt{e}))$ and $(\mu+\sigma,(1 / \sqrt{e}))$, respectively, expressed as (blue-colored lines in Figure 2)

$$
f(x)= \begin{cases}\frac{1}{\sigma \sqrt{e}} x+\frac{2 \sigma-\mu}{\sigma \sqrt{e}}, & x \leq \mu, \\ -\frac{1}{\sigma \sqrt{e}} x+\frac{2 \sigma+\mu}{\sigma \sqrt{e}}, & x>\mu .\end{cases}
$$

$f(x)$ intersects vertex tangent $g(x)=1$ (black-colored line in Figure 2) at $(\mu-2 \sigma+\sigma \sqrt{e}, 1)$ and $(\mu+2 \sigma-\sigma \sqrt{e}, 1)$ and intersects $X$ axis at $(\mu-2 \sigma, 0)$ and $(\mu+2 \sigma, 0)$. The area surrounded by $f(x), g(x)$, and $X$ axis serves as the approximation of the area under the normal distribution curve between $\mu-2 \sigma$ and $\mu+2 \sigma$. According to the empirical rule of normal distribution, about $95 \%$ of the area under the curve falls within two standard deviations (i.e., between $\mu-2 \sigma$ and $\mu+2 \sigma$ ), while $99.7 \%$ of the area under the curve falls within three standard deviations (i.e., between $\mu-3 \sigma$ and $\mu+3 \sigma$ ). In other words, the adoption of $(\mu-2 \sigma, 0)$ and $(\mu+2 \sigma, 0)$ to approximately substitute the boundaries of $\mu \tilde{\mathrm{A}}(x)$ is less accurate compared with adoption of $(\mu-3 \sigma, 0)$ and $(\mu+3 \sigma, 0)$ as approximate boundaries. Accordingly, the line determined by $(\mu \pm 3 \sigma, 0)$ and $\left(\mu \pm 2 \sigma,\left(1 / e^{2}\right)\right)$ $\left(\left(1 / e^{2}\right)\right.$ is the value of $\mu \tilde{\mathrm{A}}(x)$ when $x=\mu \pm 2 \sigma$, i.e., $\left.\mu \tilde{\mathrm{A}}(\mu \pm 2 \sigma)\right)$ is drawn, expressed as (green-colored lines in Figure 2)

$$
h(x)= \begin{cases}\frac{1}{\sigma e^{2}} x+\frac{3 \sigma-\mu}{\sigma e^{2}}, & x \leq \mu, \\ -\frac{1}{\sigma e^{2}} x+\frac{3 \sigma+\mu}{\sigma e^{2}}, & x>\mu .\end{cases}
$$


$h(x)$ intersects $f(x)$ at $(\mu-2 \sigma+(\sigma / e \sqrt{e}-1)$, $\left.\left(1 /\left(e^{2}-\sqrt{e}\right)\right)\right)$ and $\left(\mu+2 \sigma-(\sigma / e \sqrt{e}-1),\left(1 /\left(e^{2}-\sqrt{e}\right)\right)\right)$ and intersects $X$ axis at $(\mu-3 \sigma, 0)$ and $(\mu+3 \sigma, 0)$. As a result, the area surrounded by $f(x), g(x), h(x)$, and $X$ axis serves as the approximation of the area under the normal distribution curve, and the NFN $\tilde{A}=(\mu, \sigma)$ can be approximately substituted by fuzzy number $\mu \tilde{\mathrm{A}}^{\prime}(x)$ (as shown in black bold lines in Figure 2):

$$
\mu \tilde{\mathrm{A}}^{\prime}(x)=\left\{\begin{array}{l}
0, \quad x \leq \mu-3 \sigma, \\
\frac{x-(\mu-3 \sigma)}{(\sigma e \sqrt{e} / e \sqrt{e}-1)}, \quad \mu-3 \sigma<x \leq \mu-2 \sigma+\frac{\sigma}{e \sqrt{e}-1}, \\
\frac{x-(\mu-2 \sigma)}{\sigma \sqrt{e}}, \quad \mu-2 \sigma+\frac{\sigma}{e \sqrt{e}-1}<x \leq \mu-2 \sigma+\sigma \sqrt{e}, \\
1, \quad \mu-2 \sigma+\sigma \sqrt{e}<x \leq \mu+2 \sigma-\sigma \sqrt{e}, \\
\frac{(\mu+2 \sigma)-x}{\sigma \sqrt{e}}, \quad \mu+2 \sigma-\sigma \sqrt{e}<x \leq \mu+2 \sigma-\frac{\sigma}{e \sqrt{e}-1}, \\
\frac{(\mu+3 \sigma)-x}{(\sigma e \sqrt{e} / e \sqrt{e}-1)}, \quad \mu+2 \sigma-\frac{\sigma}{e \sqrt{e}-1}<x \leq \mu+3 \sigma, \\
0, \quad x>\mu+3 \sigma .
\end{array}\right.
$$

The centroid point $(\bar{x}, \bar{y})$ of fuzzy number $\mu \tilde{\mathrm{A}}^{\prime}(x)$ can be calculated according to [35], and consequently,

$$
\begin{aligned}
& \bar{x}=\mu, \\
& \bar{y}=\frac{1}{3}\left(\frac{1}{e^{2}-\sqrt{e}}\right) .
\end{aligned}
$$

While the modified $\mathrm{CV}$ method is invalid in certain situations, as discussed in 3.3.1, the centroid point method of fuzzy number ranking also has its shortcomings. For example, $\operatorname{TFN} \tilde{A}=(1,2,6)$ and $\operatorname{TFN} \tilde{A}=(2,3,4)$ have same value of $\bar{x}$ and $\bar{y}$ and accordingly same value of $R(A)=\sqrt{\bar{x}^{2}+\bar{y}^{2}}$. In such cases, the centroid point method fails to perform the ranking result. Therefore, the two alternative ranking methods of fuzzy numbers compensate each other, and the combined application of the two approach can provide satisfactory results while single application fails to give the ranking in some circumstances.

\section{Description of an Industrial Application}

In this paper, a footwear manufacturer named EA is examined to illustrate the application of the proposed fuzzy VSM in two forms, respectively, to incorporate variability in value stream analysis. The investigated factory is a final assembly plant with a production line for "cut-throughassembly" products, which, in this case, are shoes. EA outsources the production of soles and imports the raw materials for the uppers in the global market. To reduce the transport costs, EA tends to place large orders in batches of

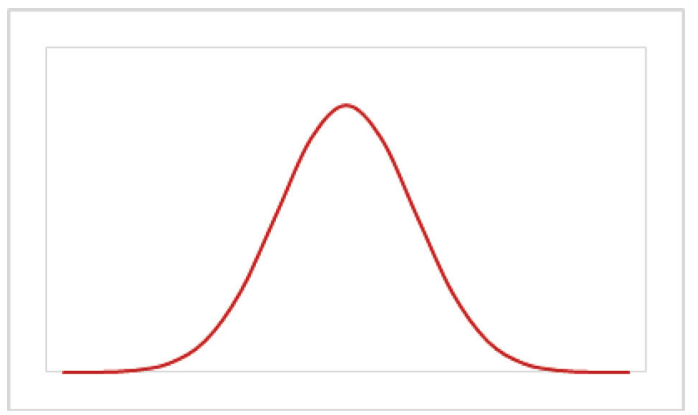

Figure 1: The membership function of an NTN $\tilde{A}$.

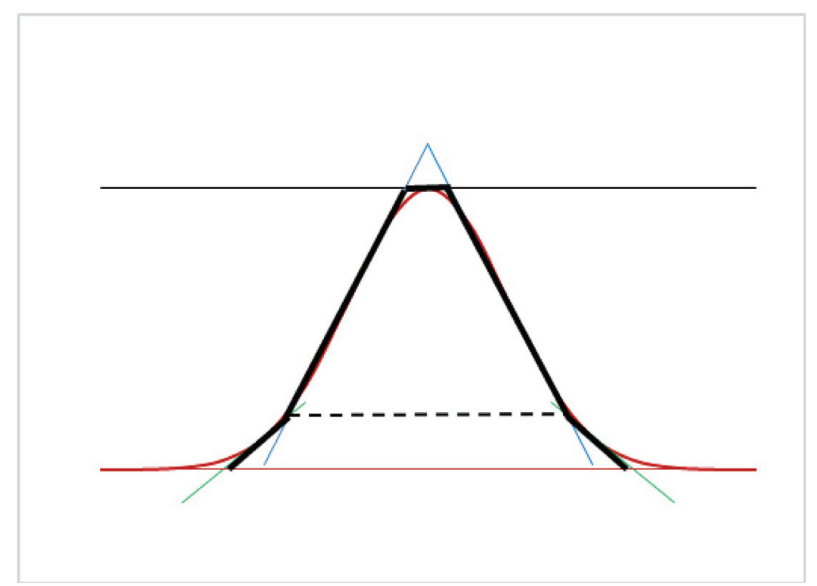

FIgURE 2: The approximate linear membership function of an NTN $\tilde{A}$.

more than 20,000 pieces on a monthly basis. The uppers are manufactured and attached to the soles in the factory. The productive process consists of a flow shop system divided into five main steps: (1) cutting, (2) prefitting, (3) computer stitching, (4) manual stitching, and (5) assembly. Production begins in the cutting room. Here, raw materials for the uppers are cut into prescribed shapes using instruments that look like cookie cutters. After cutting is prefitting, in which some of the cut parts are skived for better fit and some are embossed or embroidered with details or logos. Next, the parts are brought to the computer stitching department, where a machine guided by computer vision joins the separate parts to the uppers, which are transformed from a flat form to a three-dimensional form. Parts that cannot be automatically stitched are taken to a manual stitching workshop. Finally, the nearly finished uppers circulate to the assembly line, where the uppers are placed and stretched on foot-shaped moulds called "lasts" and attached to the soles.

The standard cycle time (i.e., the designed processing time according to the technical process plus the necessary preparation and changeover times) for cutting, prefitting, computer stitching, manual stitching, and assembly is 20, 30, 320,300 , and $510 \mathrm{~s}$, respectively. For each shoe, five different parts, including the upper body, shoe tongue, heel counter, and other functional or decorative pieces, need to be cut from the fabric or leather rolls. A cutting machine can handle up to ten tiers of flat stock at a time and a prefitting 
machine can process up to ten pieces at a time. To obtain actual operational data, field research was conducted to record the cycle time of each process and the sizes of the raw materials, buffer inventories, and finished products along the production line. The data collection is carefully designed to consider the various factors influencing variability. More specifically, in cycle time collection, the gathered data for each production process includes data from different product groups, operators, machines, times of day, and environmental conditions, such as temperature, humidity, and ambient noise. For the data collection, 100 groups of data were gathered and carefully examined by EA's experts to produce an adequate sample for further analysis. Similarly, data relevant to the volume of raw materials, WIP, and finished products were gathered. The time intervals can be expressed in the form of TFNs according to equations (2)-(4) (see Table 1 for details).

With the 100 groups of observation data (see Table 2 for details), the descriptive statistics of the sample were acquired, as shown in Table 3. The results of the Kolmogorov-Smirnov test provide the significance value (sig.) for every sample data that exceed 0.05 , which is consistent with the hypothesis of the normal distribution (see Table 4 for the results of the Kolmogorov-Smirnov test in SPSS).

Accordingly, the normal fuzzy numbers of the time duration of each stage can be obtained and expressed as $\tilde{A}=(\mu, \sigma)$ (see Table 5 for details).

EA's manufacturing plant is directed by an ERP production control system that sends a daily schedule to the shipping department and a weekly schedule to each separate workstation. The current state value stream map in the manufacturing plant is shown in Figure 3. At the bottom of the figure, the timelines for the standard, triangular fuzzy, and normal fuzzy approaches are depicted. Note that the valued-added times of cutting and prefitting are five times of their respective cycle times because the cutting and prefitting operation, respectively, repeats five times to produce the five different parts for every single shoe. It can be observed from the current-state map that the total production lead time in days (TPLT) is 8.5 days, whereas the total value-added time in seconds (TVAT) is only $23 \mathrm{~min}$, leaving a great margin for improvement.

Using the triangular fuzzy timeline, TPLT (days) can be described as TFN A $\sim(3.06,8.82,16.59)$ with the following membership functions:

$$
\mu A(x)=\left\{\begin{array}{l}
0, \quad x<3.06, \\
\frac{x-3.06}{5.76}, \quad 3.06 \leq x \leq 8.82, \\
\frac{16.59-x}{7.77}, \quad 8.82 \leq x \leq 16.59, \\
0, \quad x>16.59 .
\end{array}\right.
$$

TVAT (min) can be described as TFN B (21.04, 22.98, 26.06) with the following membership functions:

$$
\mu B(x)= \begin{cases}0, \quad x<21.04, \\ \frac{x-21.04}{1.94}, & 21.04 \leq x \leq 22.98, \\ \frac{26.06-x}{3.08}, & 22.98 \leq x \leq 26.06, \\ 0, \quad x>26.06 .\end{cases}
$$

Alternatively, using the normal fuzzy timeline, TPLT (days) can be described as NFN A (8.82, 2.53) with the following membership function:

$$
\mu A(x)=e^{-\left((x-8.82)^{2} / 12.8\right)} .
$$

TVAT (mins) can be described as NFN B $(23,0.79)$ with the following membership function:

$$
\mu B(x)=e^{-\left((x-23)^{2} / 1.25\right)} .
$$

Having noticed the low efficiency of the production processes in the current situation, EA could make some modifications in the production line to reduce waste and improve overall performance. Two alternative future-state VSMs were designed accordingly and characterized by the following modifications of the original production processes:

(i) The reoriented value stream is to be balanced on a Takt time of 36 seconds per shoe that corresponded to the demand for 400 pairs a day.

(ii) A daily Heijunka schedule is to be followed in order to achieve a quick response to the pull of customers and low changeover times.

(iii) Supermarket and kanban systems are to be applied to the production line in order to replace WIP and prevent overproduction. A supermarket is to be set up at the beginning of the internal value stream with a withdrawal kanban system in order to instruct material handlers to obtain and transfer items from the supermarket to the cutting stage. Materials are to be delivered to the production line on a daily routine. Therefore, the maximum capacity of this supermarket is to be set to 8 hours. To regulate the final assembly in accordance with the pace of the shipping schedule, another supermarket and kanban systems are to be arranged at the end of the internal value stream before the finished products are shipped. Shipping is to be arranged on a daily basis. Therefore, the maximum capacity of this supermarket will equal 8 hours.

(iv) The production line is to be levelled by a CONWIP system with production cards cycling from the assembly unit to the cutting stage via the whole production process and back to the assembly unit.

Differences among the two alternative solutions are as follows. The first solution of the future-state value stream 
TABLE 1: TFNs corresponding to cycle time and WIP.

\begin{tabular}{lcccc}
\hline & & Observed value & & TFN \\
& Min. & Mean & Max. & $(1.11,2.01,2.78)$ \\
Raw material inventory (days) & 1.2 & 2.01 & 2.7 & $(15.57,19.84,24.46)$ \\
Cutting (s) & 16 & 19.84 & 24 & $(0.24,0.80,1.47)$ \\
Buffer 1 (days) & 0.3 & 0.80 & 1.4 & $(26.66,30.05,34.44)$ \\
Prefitting (s) & 27 & 30.05 & 34 & $(1.06,1.49,2.06)$ \\
Buffer 2 (days) & 1.1 & 1.49 & 2.0 & $(301.04,320.60,335.49)$ \\
Computer stitching (s) & 303 & 320.60 & 334 & $(0,0.43,0.84)$ \\
Buffer 3 (days) & 0 & 0.43 & 0.8 & $(268.00,298.06,330.22)$ \\
Manual stitching (s) & 271 & 298.06 & 327 & $(0.34,1.91,4.68)$ \\
Buffer 4 (days) & 0.5 & 1.91 & 4.4 & $(482.16,510.58,551.05)$ \\
Assembly (s) & 485 & 510.58 & 547 & $(0.31,2.18,4.76)$ \\
Buffer 5 (days) & 0.5 & 2.18 & 4.5 & $(0.5)$ \\
\hline
\end{tabular}

(see Figure 4) is supposed to change the layout of the plant to move the cutting and the prefitting units closer to each other, to realize the operator shifts between the two units four times a day. Such a modification is to be made after the productivity of each production process and the Takt time of the whole value stream (36 s per shoe) are compared. In particular, for cutting and prefitting, the processing times of an upper are $100 \mathrm{~s}$ and $150 \mathrm{~s}$, respectively (as previously mentioned, five times per cycle time of a device). However, the concurrent output of these two processes is ten items. Therefore, the times required to produce one item by these two processes are $10 \mathrm{~s}$ and $15 \mathrm{~s}$, respectively. For computer stitching, manual stitching, and assembly, the number of facilities working concurrently is 10,10 , and 15 while the corresponding cycle times are $320 \mathrm{~s}, 300 \mathrm{~s}$, and $510 \mathrm{~s}$, respectively. Each machine can handle a single shoe at a time. Therefore, the output paces of these three processes are 32, 30, and $34 \mathrm{~s}$ per shoe, respectively. Table 6 lists the cycle time and WIP of each production process in this solution.

The cutting and prefitting have output paces, as measured by the time taken to produce one item (10 s and $15 \mathrm{~s}$, respectively), of less than half of the Takt time of the line. Therefore, the proposal of shift working in cutting and prefit processes is generated, as indicated by the arrow connecting cutting and prefitting in Figure 4. In accordance with this hypothesis, the line is balanced under the condition that the cutting unit works on half shift but keeps its original productive rate. Hence, it is necessary to place a buffer immediately after the cutting unit to store the items released at a rate that is double that of the line. A supermarket is placed after the prefitting unit to inform the production kanban of the number of items to be produced. Such a modification makes it possible to reduce not only WIP volumes but also labor density. When it goes to the computer stitching, manual stitching, and assembly departments, the batch approach is replaced by the flow approach. First-in-first-out (FIFO) inventory stocking with a maximum of two pairs is implemented between the cells of two adjacent departments. As a result, the production lead time drops from 8.5 days in the initial "push" line to 14 hours through significant attention to process improvement and the reduction of WIP.
In the second solution (see Figure 5), the hypothesis is to change the overall layout of the plant to unify the cutting and the prefitting units into a single cell and the computer and manual stitching units into another to realize a "one-piece" flow within the working cells.

The cutting and prefitting production unit is operated by one worker handling ten pieces as a batch without interruption or delay between the two steps. Similarly, in the computer and manual stitching cells, an upper flows directly from the computer to the manual stitching without temporary storage to eliminate the WIP between the two processes in the same production cell and reduce unnecessary transporting due to the isolation of the two departments as in the original plant layout. The stitched uppers are sent to the assembly line following a FIFO lane with a maximum of two pairs. Consequently, the production rate of the computer and manual stitching cell is directed by the assembly line. The pace of the cutting and prefitting cell can be determined by setting a supermarket system between the two production cells. Table 7 lists the cycle time and WIP of each production process in this solution.

In the form of TFN, TPLT 1 (in hours) can be described by TFN $A_{1} \sim(2.88,14,25.1)$, whereas TPLT $_{2}$ (in hours) can be described by TFN $\mathrm{A}_{2} \sim(-0.44,9,18.44)$. $\mathrm{TPLT}_{2}$ has a negative value, which would be illogical and unrealistic in a real case. Having examined the calculation process of TPLT, it is discovered that the irrationality was due to the simple summation of the separate lead times. More specifically, the two supermarkets at the beginning and end of the production line cannot reach their respective lower limits at the same time.

At the beginning of a day, the supermarket at the beginning of the line holds the maximum volume because the external materials have just arrived, whereas the supermarket at the end of the line holds the minimum volume because no product is ready for shipping yet. In contrast, at the end of a day, the supermarket at the beginning of the line holds the minimum volume because all external materials have been delivered to the productive processes, whereas the supermarket at the end of the line holds the maximum volume with finished products waiting to be shipped. Consequently, the summation of the items in these two supermarkets is in balance with an average of 8 hours in a 24-hour period. Similarly, due to the negative correlation 
TABLE 2: Data recorded for the value stream.

\begin{tabular}{|c|c|c|c|c|c|c|c|c|c|c|c|}
\hline & $\begin{array}{c}\text { Raw material } \\
\text { inventory } \\
\text { (days) }\end{array}$ & $\begin{array}{l}\text { Cutting } \\
\text { (s) }\end{array}$ & $\begin{array}{c}\text { Buffer } 1 \\
\text { (days) }\end{array}$ & $\begin{array}{l}\text { Prefitting } \\
\text { (s) }\end{array}$ & $\begin{array}{l}\text { Buffer } 2 \\
\text { (days) }\end{array}$ & $\begin{array}{c}\text { Computer } \\
\text { stitching (s) }\end{array}$ & $\begin{array}{c}\text { Buffer } 3 \\
\text { (days) }\end{array}$ & $\begin{array}{l}\text { Manual } \\
\text { stitching } \\
(\mathrm{s})\end{array}$ & $\begin{array}{l}\text { Buffer } 4 \\
\text { (days) }\end{array}$ & $\begin{array}{l}\text { Assembly } \\
\text { (s) }\end{array}$ & $\begin{array}{c}\text { Buffer } 5 \\
\text { (days) }\end{array}$ \\
\hline (1) & 1.9 & 23 & 0.6 & 30 & 1.5 & 310 & 0.6 & 324 & 2.5 & 511 & 3.4 \\
\hline (2) & 1.8 & 20 & 1.2 & 28 & 1.7 & 317 & 0.5 & 299 & 2.6 & 496 & 2 \\
\hline (3) & 2.2 & 21 & 0.4 & 27 & 1.3 & 325 & 0.4 & 273 & 1.8 & 531 & 2.9 \\
\hline (4) & 2 & 19 & 0.6 & 32 & 1.5 & 322 & 0.3 & 300 & 1.9 & 509 & 3 \\
\hline (5) & 1.9 & 22 & 0.9 & 29 & 1.6 & 319 & 0.1 & 310 & 0.5 & 493 & 2.2 \\
\hline (6) & 2.3 & 20 & 0.6 & 31 & 1.4 & 333 & 0.4 & 305 & 1.1 & 505 & 4 \\
\hline (7) & 2.1 & 19 & 0.6 & 31 & 1.6 & 331 & 0.5 & 311 & 0.7 & 508 & 1.8 \\
\hline (8) & 2.1 & 18 & 0.5 & 33 & 1.6 & 321 & 0.5 & 295 & 1.7 & 528 & 4.2 \\
\hline (9) & 1.5 & 19 & 0.7 & 30 & 1.2 & 320 & 0.4 & 315 & 0.5 & 504 & 1.9 \\
\hline (10) & 2 & 22 & 0.9 & 30 & 1.4 & 322 & 0.4 & 306 & 3.5 & 547 & 1.8 \\
\hline (11) & 1.9 & 21 & 1.1 & 31 & 1.4 & 319 & 0.6 & 298 & 2.4 & 522 & 2.6 \\
\hline (12) & 2.4 & 20 & 0.6 & 30 & 1.4 & 315 & 0.5 & 307 & 3 & 520 & 3.1 \\
\hline (13) & 2 & 19 & 0.3 & 30 & 1.4 & 328 & 0.5 & 291 & 2.2 & 503 & 0.5 \\
\hline (14) & 1.2 & 22 & 0.8 & 31 & 1.4 & 323 & 0.2 & 292 & 1.2 & 525 & 0.7 \\
\hline (15) & 2 & 21 & 1 & 32 & 1.4 & 303 & 0 & 287 & 1.2 & 514 & 1.5 \\
\hline (16) & 2.2 & 16 & 0.7 & 27 & 1.7 & 314 & 0.3 & 303 & 2.4 & 530 & 1.1 \\
\hline (17) & 2.5 & 20 & 0.9 & 33 & 1.3 & 321 & 0.2 & 279 & 0.5 & 515 & 2.6 \\
\hline (18) & 1.5 & 19 & 0.7 & 31 & 1.6 & 327 & 0.4 & 271 & 1.7 & 494 & 2 \\
\hline (19) & 2.1 & 21 & 1.1 & 27 & 1.6 & 315 & 0.5 & 299 & 1.8 & 506 & 1.2 \\
\hline (20) & 2.2 & 20 & 0.9 & 32 & 1.5 & 315 & 0.6 & 296 & 1 & 512 & 2 \\
\hline (21) & 1.5 & 23 & 0.6 & 33 & 1.5 & 323 & 0.2 & 300 & 0.5 & 492 & 3.4 \\
\hline (22) & 2.5 & 20 & 0.8 & 31 & 1.2 & 324 & 0.7 & 311 & 0.5 & 506 & 1.9 \\
\hline (23) & 1.7 & 21 & 1 & 29 & 1.6 & 329 & 0.4 & 297 & 1.5 & 495 & 2.5 \\
\hline (24) & 2 & 22 & 1 & 31 & 1.6 & 327 & 0.7 & 318 & 1.7 & 514 & 2.1 \\
\hline (25) & 2.4 & 20 & 0.8 & 28 & 1.2 & 315 & 0.4 & 293 & 1.3 & 518 & 2.4 \\
\hline (26) & 2.2 & 20 & 0.8 & 31 & 1.5 & 314 & 0.2 & 305 & 1.2 & 536 & 2.6 \\
\hline (27) & 2.6 & 20 & 1.2 & 31 & 1.5 & 318 & 0.3 & 295 & 2.3 & 531 & 3.5 \\
\hline (28) & 2.3 & 20 & 0.7 & 28 & 1.6 & 326 & 0.5 & 295 & 1.2 & 519 & 3 \\
\hline (29) & 2 & 20 & 0.9 & 31 & 1.4 & 325 & 0.6 & 309 & 2.1 & 492 & 1.9 \\
\hline (30) & 1.7 & 21 & 0.9 & 30 & 1.6 & 314 & 0.5 & 288 & 1.9 & 496 & 2.7 \\
\hline (31) & 1.8 & 19 & 0.8 & 29 & 1.4 & 317 & 0.7 & 294 & 1.9 & 518 & 3.5 \\
\hline (32) & 2.3 & 17 & 1 & 31 & 1.2 & 318 & 0.6 & 327 & 2.3 & 518 & 2.8 \\
\hline (33) & 1.9 & 21 & 1 & 30 & 1.5 & 333 & 0.5 & 277 & 1.8 & 527 & 1.3 \\
\hline (34) & 2.6 & 20 & 1 & 29 & 1.4 & 317 & 0.4 & 303 & 1.8 & 489 & 2 \\
\hline (35) & 1.6 & 24 & 0.6 & 29 & 1.6 & 323 & 0.4 & 300 & 3.2 & 500 & 2.4 \\
\hline (36) & 2.1 & 22 & 1.1 & 30 & 1.6 & 318 & 0.4 & 280 & 2 & 505 & 2.1 \\
\hline (37) & 2.1 & 17 & 1.2 & 29 & 1.3 & 326 & 0.3 & 283 & 4.4 & 518 & 3.4 \\
\hline (38) & 1.9 & 20 & 0.6 & 27 & 1.3 & 326 & 0.2 & 296 & 2.5 & 521 & 2.7 \\
\hline (39) & 2 & 19 & 0.7 & 31 & 1.4 & 323 & 0.5 & 289 & 3.3 & 510 & 2.4 \\
\hline (40) & 1.5 & 19 & 0.6 & 30 & 1.5 & 310 & 0.5 & 290 & 2.7 & 493 & 1.4 \\
\hline (41) & 2 & 19 & 0.9 & 31 & 1.3 & 327 & 0.2 & 314 & 2.6 & 502 & 1.6 \\
\hline (42) & 2.2 & 18 & 0.9 & 32 & 1.5 & 313 & 0.5 & 296 & 1.6 & 487 & 0.8 \\
\hline (43) & 2 & 22 & 0.6 & 32 & 1.6 & 308 & 0.5 & 298 & 3 & 523 & 1.5 \\
\hline (44) & 2.1 & 19 & 0.6 & 30 & 1.6 & 325 & 0.7 & 286 & 2.4 & 506 & 3 \\
\hline (45) & 2.5 & 19 & 0.3 & 30 & 1.3 & 328 & 0.6 & 307 & 3.2 & 514 & 1.6 \\
\hline (46) & 2.2 & 19 & 0.7 & 29 & 1.6 & 314 & 0.6 & 287 & 2.7 & 510 & 0.5 \\
\hline (47) & 2 & 18 & 0.5 & 29 & 1.7 & 333 & 0.3 & 289 & 2 & 510 & 1.4 \\
\hline (48) & 2 & 17 & 0.9 & 28 & 1.4 & 318 & 0.4 & 297 & 1.9 & 520 & 1.7 \\
\hline (49) & 2 & 22 & 1.4 & 30 & 2.0 & 311 & 0.4 & 308 & 3.1 & 519 & 4.5 \\
\hline (50) & 2.1 & 21 & 0.8 & 29 & 1.5 & 316 & 0.4 & 306 & 3.7 & 506 & 2.7 \\
\hline (51) & 2 & 20 & 0.7 & 32 & 1.5 & 322 & 0.6 & 294 & 1 & 502 & 2 \\
\hline (52) & 1.7 & 20 & 0.8 & 32 & 1.4 & 322 & 0.3 & 304 & 2.4 & 505 & 2.1 \\
\hline (53) & 2.3 & 21 & 0.8 & 31 & 1.7 & 322 & 0.7 & 292 & 1.3 & 507 & 2.2 \\
\hline (54) & 1.9 & 20 & 1 & 31 & 1.6 & 327 & 0.1 & 307 & 2.5 & 508 & 2.1 \\
\hline (55) & 1.5 & 21 & 1 & 34 & 1.4 & 320 & 0.2 & 301 & 2.4 & 488 & 2.2 \\
\hline (56) & 1.6 & 21 & 1 & 28 & 1.5 & 317 & 0.4 & 275 & 1.4 & 519 & 2.7 \\
\hline (57) & 2 & 17 & 0.8 & 31 & 1.7 & 319 & 0.7 & 319 & 1.3 & 502 & 2.5 \\
\hline (58) & 2.1 & 17 & 0.9 & 30 & 1.7 & 323 & 0.3 & 286 & 3 & 506 & 1.7 \\
\hline (59) & 2 & 19 & 0.7 & 29 & 1.7 & 320 & 0.7 & 299 & 2.4 & 530 & 1.5 \\
\hline
\end{tabular}


TABle 2: Continued.

\begin{tabular}{|c|c|c|c|c|c|c|c|c|c|c|c|}
\hline & $\begin{array}{c}\text { Raw material } \\
\text { inventory } \\
\text { (days) }\end{array}$ & $\begin{array}{l}\text { Cutting } \\
\text { (s) }\end{array}$ & $\begin{array}{l}\text { Buffer } 1 \\
\text { (days) }\end{array}$ & $\begin{array}{l}\text { Prefitting } \\
\text { (s) }\end{array}$ & $\begin{array}{l}\text { Buffer } 2 \\
\text { (days) }\end{array}$ & $\begin{array}{c}\text { Computer } \\
\text { stitching (s) }\end{array}$ & $\begin{array}{c}\text { Buffer } 3 \\
\text { (days) }\end{array}$ & $\begin{array}{l}\text { Manual } \\
\text { stitching } \\
\text { (s) }\end{array}$ & $\begin{array}{c}\text { Buffer } 4 \\
\text { (days) }\end{array}$ & $\begin{array}{l}\text { Assembly } \\
\text { (s) }\end{array}$ & $\begin{array}{c}\text { Buffer } 5 \\
\text { (days) }\end{array}$ \\
\hline$(60)$ & 1.8 & 18 & 0.8 & 30 & 1.6 & 311 & 0.6 & 304 & 1.1 & 494 & 2.8 \\
\hline (61) & 2.3 & 19 & 0.9 & 31 & 1.5 & 315 & 0.4 & 286 & 0.9 & 499 & 2.4 \\
\hline (62) & 1.7 & 17 & 0.6 & 28 & 1.4 & 327 & 0.5 & 309 & 2.4 & 516 & 1.7 \\
\hline (63) & 1.6 & 18 & 0.9 & 29 & 1.6 & 320 & 0.3 & 285 & 2.5 & 494 & 2.3 \\
\hline (64) & 2.2 & 18 & 0.6 & 27 & 1.5 & 329 & 0.4 & 297 & 1.1 & 508 & 3.3 \\
\hline (65) & 1.8 & 20 & 0.8 & 31 & 1.5 & 310 & 0.6 & 288 & 1.5 & 521 & 2.3 \\
\hline (66) & 2.1 & 22 & 0.9 & 29 & 1.5 & 325 & 0.3 & 305 & 1.2 & 516 & 1.1 \\
\hline (67) & 1.9 & 17 & 0.3 & 29 & 1.4 & 320 & 0.3 & 293 & 1.6 & 506 & 2.7 \\
\hline (68) & 2.1 & 19 & 0.8 & 29 & 1.3 & 320 & 0.3 & 309 & 1.3 & 516 & 1.8 \\
\hline (69) & 2 & 17 & 0.5 & 28 & 1.3 & 326 & 0.4 & 294 & 1.9 & 505 & 1.4 \\
\hline (70) & 2 & 17 & 1.2 & 31 & 1.7 & 328 & 0.3 & 289 & 2.5 & 509 & 1 \\
\hline (71) & 1.9 & 19 & 0.8 & 28 & 1.3 & 311 & 0.2 & 298 & 1.1 & 505 & 2.8 \\
\hline (72) & 1.8 & 21 & 0.7 & 30 & 1.1 & 322 & 0.7 & 290 & 2.8 & 518 & 1.3 \\
\hline (73) & 2.4 & 22 & 0.7 & 29 & 1.6 & 324 & 0.2 & 284 & 1.2 & 509 & 2.3 \\
\hline (74) & 2.5 & 21 & 0.6 & 30 & 1.3 & 323 & 0.5 & 313 & 2.9 & 531 & 1.9 \\
\hline (75) & 2.3 & 19 & 0.5 & 28 & 1.5 & 310 & 0.4 & 283 & 0.9 & 516 & 1.8 \\
\hline (76) & 1.2 & 18 & 0.8 & 28 & 1.5 & 323 & 0.4 & 315 & 1.9 & 506 & 1.5 \\
\hline (77) & 2.2 & 19 & 0.8 & 30 & 1.4 & 323 & 0.4 & 303 & 1.9 & 489 & 1.4 \\
\hline (78) & 2 & 23 & 1.4 & 30 & 1.4 & 326 & 0.7 & 317 & 2.2 & 525 & 2 \\
\hline (79) & 2.6 & 22 & 0.7 & 27 & 1.8 & 324 & 0.5 & 290 & 1.6 & 522 & 2.1 \\
\hline (80) & 2.1 & 21 & 1.2 & 33 & 1.7 & 320 & 0.5 & 290 & 0.8 & 540 & 1.2 \\
\hline (81) & 2 & 19 & 1 & 29 & 1.7 & 326 & 0.5 & 296 & 1.7 & 522 & 3.1 \\
\hline (82) & 2.4 & 21 & 1 & 32 & 1.3 & 325 & 0.5 & 290 & 2.8 & 505 & 1.2 \\
\hline (83) & 2 & 21 & 0.8 & 29 & 1.4 & 325 & 0.4 & 292 & 2.4 & 516 & 1.4 \\
\hline (84) & 1.7 & 19 & 0.4 & 29 & 1.5 & 320 & 0.6 & 296 & 0.7 & 511 & 4.2 \\
\hline (85) & 1.8 & 18 & 1.1 & 28 & 1.5 & 316 & 0.5 & 285 & 0.8 & 515 & 1.1 \\
\hline (86) & 2 & 19 & 0.7 & 29 & 1.6 & 315 & 0.3 & 300 & 0.6 & 516 & 1.9 \\
\hline (87) & 1.9 & 24 & 1.1 & 30 & 1.3 & 312 & 0.4 & 301 & 2.3 & 501 & 1.2 \\
\hline (88) & 1.5 & 23 & 0.7 & 32 & 1.6 & 316 & 0.2 & 312 & 3 & 519 & 2.2 \\
\hline (89) & 1.3 & 24 & 0.9 & 33 & 1.5 & 327 & 0.7 & 306 & 0.5 & 485 & 0.9 \\
\hline (90) & 1.9 & 20 & 0.7 & 30 & 1.4 & 334 & 0.3 & 289 & 2.8 & 493 & 3.4 \\
\hline (91) & 2 & 19 & 0.8 & 32 & 1.6 & 316 & 0.4 & 315 & 1.4 & 514 & 2.3 \\
\hline (92) & 2.2 & 23 & 0.8 & 30 & 1.6 & 316 & 0.4 & 288 & 1.4 & 524 & 2.2 \\
\hline (93) & 2.7 & 18 & 0.9 & 29 & 1.4 & 323 & 0.5 & 304 & 2.3 & 491 & 2.8 \\
\hline (94) & 1.9 & 18 & 0.3 & 31 & 1.2 & 325 & 0.5 & 292 & 2.4 & 525 & 3.5 \\
\hline (95) & 1.9 & 16 & 1 & 31 & 1.5 & 316 & 0.2 & 297 & 1.1 & 496 & 1.4 \\
\hline (96) & 2 & 18 & 0.3 & 29 & 1.6 & 319 & 0.7 & 303 & 3.2 & 509 & 2.2 \\
\hline (97) & 2.2 & 24 & 0.8 & 32 & 1.5 & 319 & 0 & 295 & 1.1 & 517 & 2.1 \\
\hline (98) & 1.4 & 17 & 0.6 & 32 & 1.4 & 333 & 0.8 & 318 & 2.2 & 508 & 2.9 \\
\hline (99) & 2.5 & 18 & 0.8 & 32 & 1.6 & 318 & 0 & 301 & 3.1 & 494 & 2.4 \\
\hline (100) & 2.1 & 21 & 1 & 30 & 1.8 & 311 & 0.6 & 308 & 1.9 & 517 & 1.7 \\
\hline Mean & 2.01 & 19.84 & 0.80 & 30.05 & 1.49 & 320.60 & 0.43 & 298.06 & 1.91 & 510.58 & 2.18 \\
\hline
\end{tabular}

TABle 3: Descriptive statistics of cycle time and WIP.

\begin{tabular}{lccc}
\hline & Range & Mean \pm Std. deviation (i.e., $\mu \pm \sigma)$ & K-S test \\
\hline Raw material inventory (days) & $(1.2,2.7)$ & $2.01 \pm 0.31$ & 0.061 \\
Cutting (s) & $(16,24)$ & $19.84 \pm 1.89$ & 0.064 \\
Buffer 1 (days) & $(0.3,1.4)$ & $0.80 \pm 0.23$ & 0.252 \\
Prefitting (s) & $(27,34)$ & $30.05 \pm 1.60$ & 0.090 \\
Buffer 2 (days) & $(1.1,2.0)$ & $1.49 \pm 0.15$ & 0.063 \\
Computer stitching (s) & $(303,334)$ & $320.60 \pm 6.25$ & 0.721 \\
Buffer 3 (days) & $(0,0.8)$ & $0.43 \pm 0.17$ & 0.055 \\
Manual stitching (s) & $(271,327)$ & $298.06 \pm 11.24$ & 0.977 \\
Buffer 4 (days) & $(0.5,4.4)$ & $1.91 \pm 0.84$ & 0.590 \\
Assembly (s) & $(485,547)$ & $510.58 \pm 12.61$ & 0.773 \\
Buffer 5 (days) & $(0.5,4.5)$ & $2.18 \pm 0.83$ & 0.705 \\
\hline
\end{tabular}




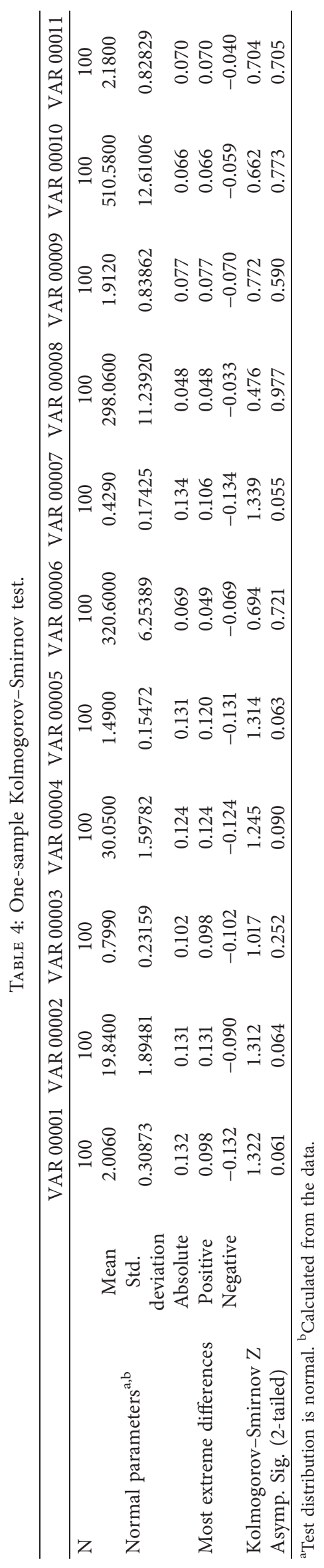


TABLE 5: The NFNs corresponding to cycle time and WIP.

\begin{tabular}{lc}
\hline & NFN \\
\hline Raw material inventory (days) & $(2.01,0.31)$ \\
Cutting (s) & $(19.84,1.89)$ \\
Buffer 1 (days) & $(0.80,0.23)$ \\
Prefitting (s) & $(30.05,1.60)$ \\
Buffer 2 (days) & $(1.49,0.15)$ \\
Computer stitching (s) & $(320.60,6.25)$ \\
Buffer 3 (days) & $(0.43,0.17)$ \\
Manual stitching (s) & $(298.06,11.24)$ \\
Buffer 4 (days) & $(1.91,0.84)$ \\
Assembly (s) & $(510.58,12.61)$ \\
Buffer 5 (days) & $(2.18,0.83)$ \\
\hline
\end{tabular}

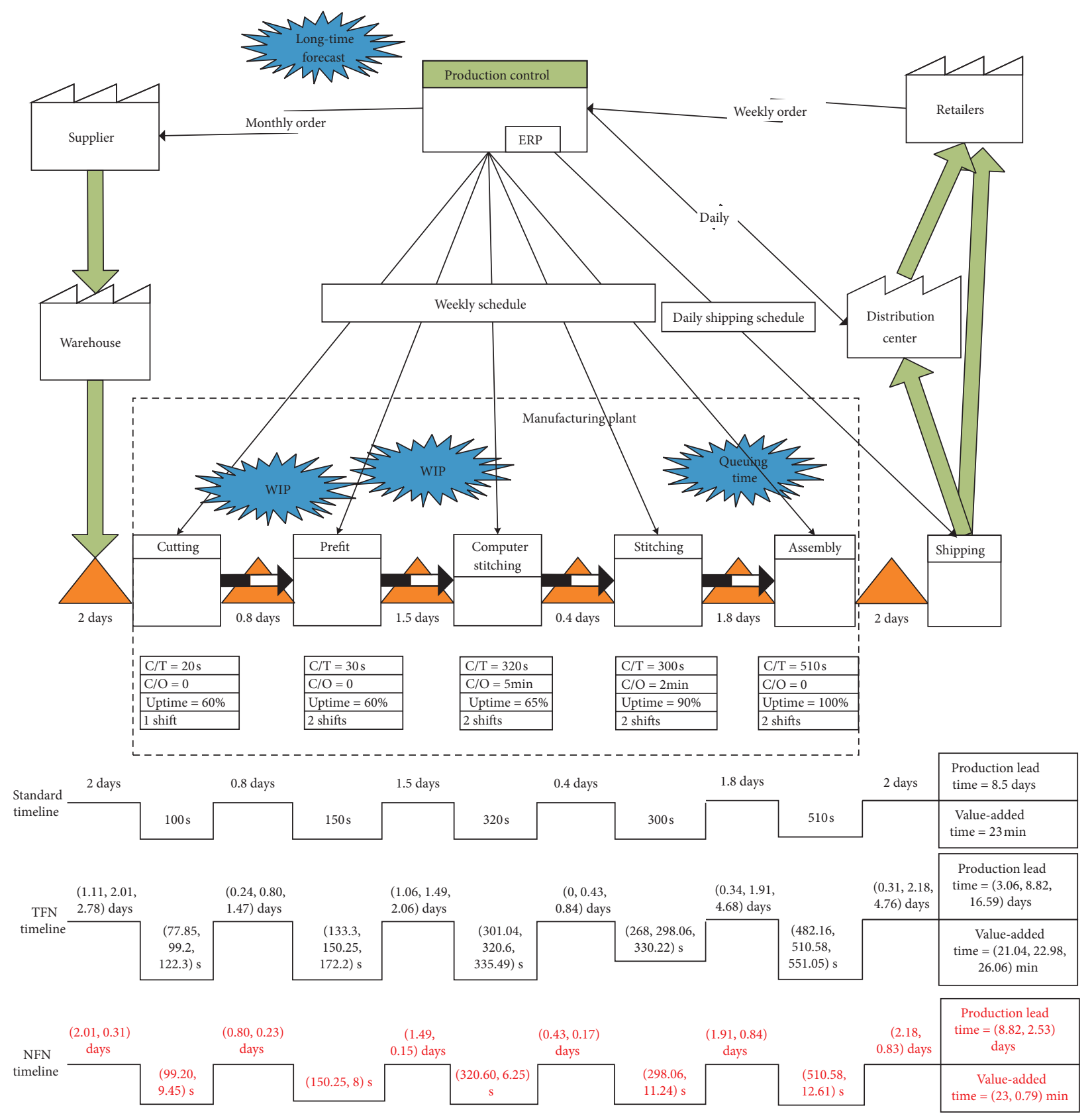

Figure 3: Current-state value stream map. 


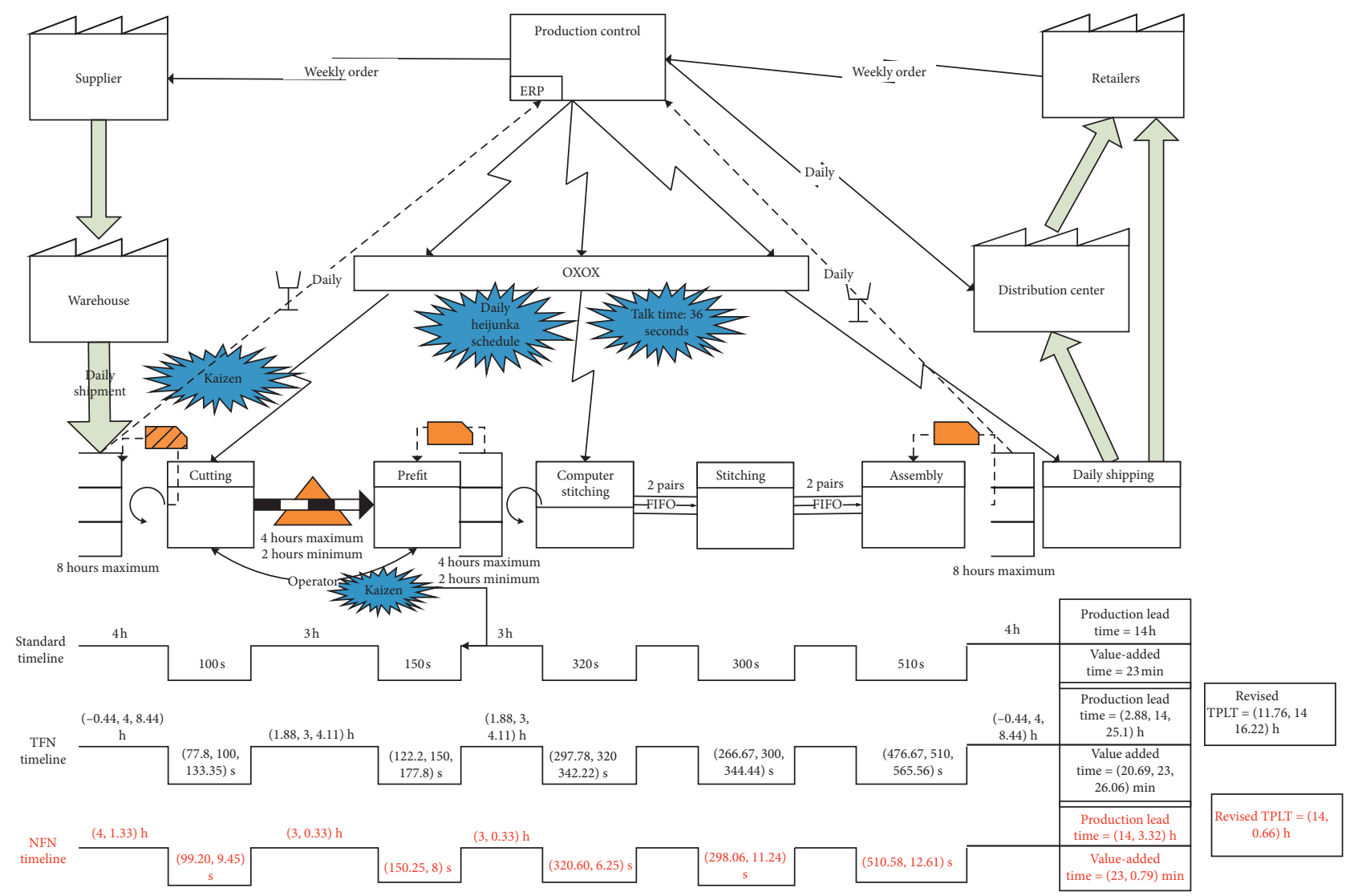

Figure 4: Future-state value stream map (1).

TABLE 6: Cycle time and WIP for future-state value stream map (1).

\begin{tabular}{|c|c|c|c|c|c|}
\hline & \multicolumn{3}{|c|}{ Estimated value } & \multirow{2}{*}{ TFN } & \multirow{2}{*}{ NFN } \\
\hline & $\mathrm{a}$ & $\mathrm{b}$ & c & & \\
\hline Raw material inventory (hours) & 0 & 4 & 8 & $(-0.44,4.00,8.44)$ & $(4.00,1.33)$ \\
\hline Cutting (s) & 16 & 20 & 26 & $(15.56,20.00,26.67)$ & $(19.84,1.89)$ \\
\hline Buffer 1 (hours) & 2 & 3 & 4 & $(1.88,3.00,4.11)$ & $(3.00,0.33)$ \\
\hline Prefitting (s) & 25 & 30 & 35 & $(24.44,30.00,35.56)$ & $(30.05,1.60)$ \\
\hline Buffer 2 (hours) & 2 & 3 & 4 & $(1.88,3.00,4.11)$ & $(3.00,0.33)$ \\
\hline Computer stitching (s) & 300 & 320 & 340 & $(297.78,320.00,342.22)$ & $(320.60,6.25)$ \\
\hline Manual stitching (s) & 270 & 300 & 340 & $(266.67,300.00,344.44)$ & $(298.06,11.24)$ \\
\hline Assembly (s) & 480 & 510 & 560 & $(476.67,510.00,565.56)$ & $(510.58,12.61)$ \\
\hline Buffer 5 (hours) & 0 & 4 & 8 & $(-0.44,4.00,8.44)$ & $(4.00,1.33)$ \\
\hline
\end{tabular}

Note: the NTNs of cutting, prefitting, computer stitching, manual stitching, and assembly do not change with the current state.

between the two supermarkets, the deviations for them are traded off against each other. Therefore, a revised TPLT for a TFN approach is placed in the two future-state maps illustrated in Figures 4 and 5.
In conclusion, using the TFN approach, the revised $\mathrm{TPLT}_{1}$ (in hours) can be described with TFN $\mathrm{A}_{1} \sim(11.76,14$, 16.22), whereas $\mathrm{TPLT}_{2}$ (in hours) can be described with TFN $\mathrm{A}_{2} \sim(8.44,9,9.56)$. 

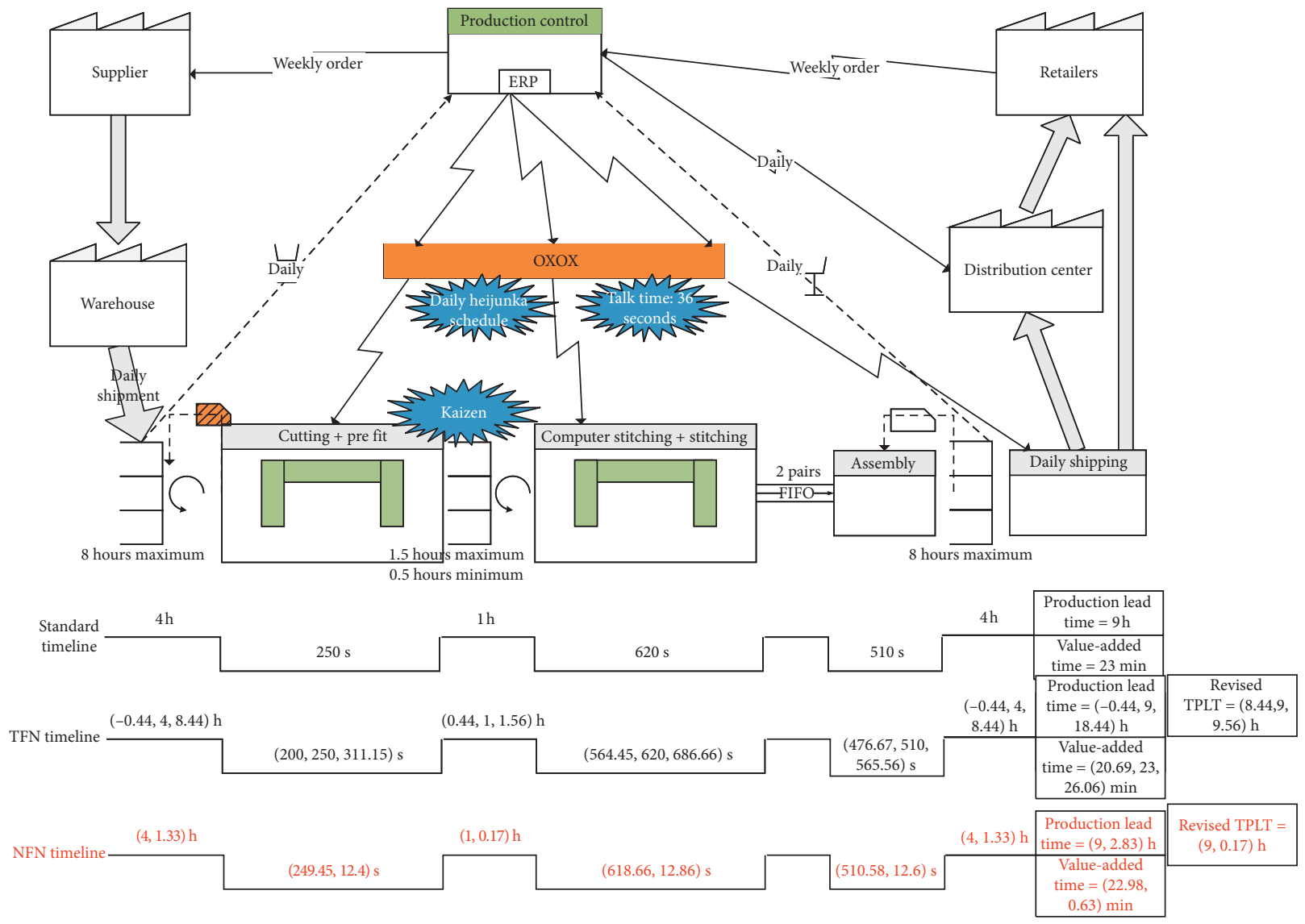

FIgURE 5: Future-state value stream map (2).

$$
\begin{aligned}
& \mu A_{1}(x)= \begin{cases}0, \quad x<11.76 \\
\frac{x-11.76}{2.24}, & 11.76 \leq x \leq 14, \\
\frac{16.22-x}{2.22}, & 14 \leq x \leq 16.22, \\
0, \quad x>16.22,\end{cases} \\
& \mu A_{2}(x)= \begin{cases}0, \quad x<8.44 \\
\frac{x-8.44}{0.56}, & 8.44 \leq x \leq 9 \\
\frac{9.56-x}{0.56}, & 9 \leq x \leq 9.56 \\
0, \quad x>9.56\end{cases}
\end{aligned}
$$

Alternatively, in the form of NTN, TPLT $_{1}$ (in hours) can be described by NFN $A_{1} \sim(14,0.66)$, whereas TPLT $_{2}$ (in hours) can be described by NFN $A_{2} \sim(9,0.17)$.

$$
\begin{gathered}
\mu A_{1}(x)=e^{-\left((x-14)^{2} / 0.871\right)}, \\
\mu A_{2}(x)=e^{-\left((x-9)^{2} / 0.058\right)} .
\end{gathered}
$$

The results of the two alternative future-state maps are graphically shown in Figure 6. Obviously, both solutions lead to significant improvements in lead time as compared to the current state (14 and 9 hours, respectively, as compared to 8.82 days). To compare the obtained solutions, the modified $\mathrm{CV}$ and centroid point method are applied, respectively. Using the modified $\mathrm{CV}$ approach, $\mu$ and $\sigma$ of TFNs $A_{1}$ and $A_{2}$ are calculated, respectively, following equation (10) and (11). According to equation (9), for TFNbased $\mathrm{VSM}_{1}$, modified CV $=\left(0.91^{\alpha} / 14^{1-\alpha}\right)$; for TFN-based $\mathrm{VSM}_{2}$, modified CV $=\left(0.23^{\alpha} / 9^{1-\alpha}\right)$; for NFN-based $\mathrm{VSM}_{1}$, modified CV $=\left(0.66^{\alpha} / 14^{1-\alpha}\right)$; and for NFN-based $\mathrm{VSM}_{2}$, modified $C V=\left(0.17^{\alpha} / 9^{1-\alpha}\right)$. Giving same weight to $\mu$ and $\sigma$, i.e., $\alpha=0.5$, the modified CV for TFN-based $\mathrm{VSM}_{1}$ and $\mathrm{VSM}_{2}$ equals 0.255 and 0.160 , respectively, and the modified CV for NFN-based $\mathrm{VSM}_{1}$ and $\mathrm{VSM}_{2}$ equals 0.217 and 0.137 , respectively. Therefore, using the modified CV approach, future-state $\mathrm{VSM}_{2}$ is superior to $\mathrm{VSM}_{1}$ in both TFN and NFN expressions. Using the centroid point method, $\bar{x}$ and $\bar{y}$ of TFNs $A_{1}$ and $A_{2}$ are calculated, respectively, according to equations (12) and (13), and $\bar{x}$ and $\bar{y}$ of NFNs $A_{1}$ and $A_{2}$ are calculated, respectively, according to equation (17) and (18). As a result, for TFN-based $\mathrm{VSM}_{1}$, $\mathrm{R}(\mathrm{A})=14$; for TFN-based $\mathrm{VSM}_{2}, \mathrm{R}(\mathrm{A})=9$; for NFN-based $\mathrm{VSM}_{1}, \mathrm{R}(\mathrm{A})=14$; and for NFN-based $\mathrm{VSM}_{2}, \mathrm{R}(\mathrm{A})=9$. As production lead time is "smaller-the-better" parameter, using the centroid point method, future-state $\mathrm{VSM}_{2}$ is 
TABLE 7: Cycle time and WIP for future-state value stream map (2).

\begin{tabular}{|c|c|c|c|c|c|}
\hline & \multicolumn{3}{|c|}{ Estimated value } & \multirow{2}{*}{ TFN } & \multirow{2}{*}{ NFN } \\
\hline & a & $\mathrm{b}$ & c & & \\
\hline Raw material inventory (hours) & 0 & 4 & 8 & $(-0.44,4.00,8.44)$ & $(4.00,1.33)$ \\
\hline Cutting + prefitting (s) & 41 & 50 & 61 & $(40.00,50.00,62.23)$ & $(49.89,2.48)$ \\
\hline Supermarket no. 1 (hours) & 0.5 & 1 & 1.5 & $(0.44,1.00,1.56)$ & $(1.00,0.17)$ \\
\hline Computer + manual stitching (s) & 570 & 620 & 680 & $(564.45,620.00,686.66)$ & $(618.66,12.86)$ \\
\hline Assembly (s) & 480 & 510 & 560 & $(476.67,510.00,565.56)$ & $(510.58,12.6)$ \\
\hline Supermarket to shipping (hours) & 0 & 4 & 8 & $(-0.44,4.00,8.44)$ & $(4.00,1.33)$ \\
\hline
\end{tabular}

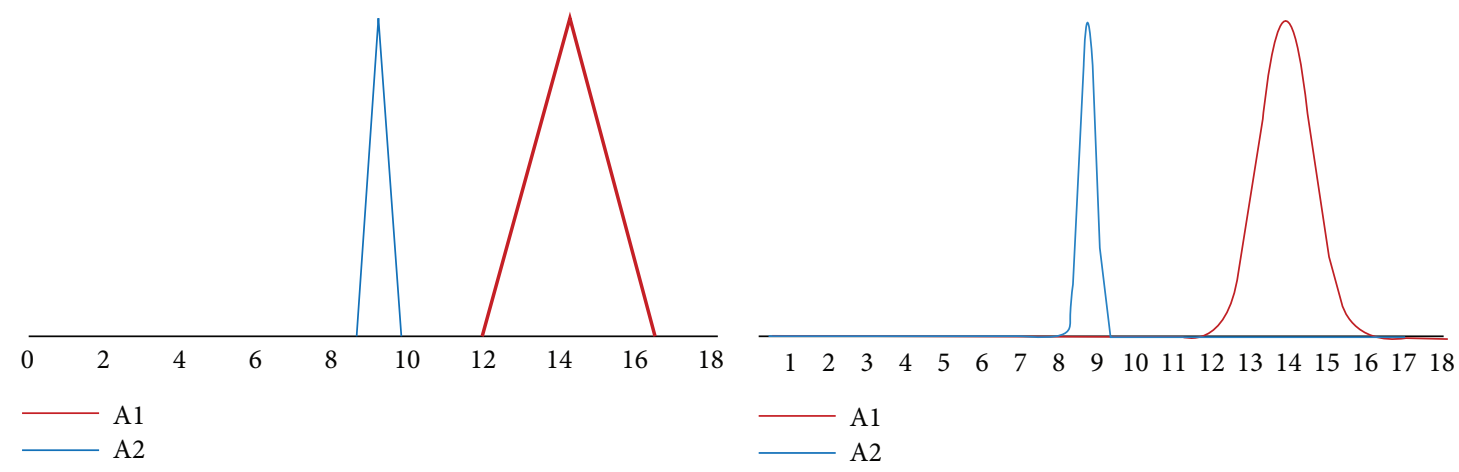

(a)

(b)

FIgURE 6: Future-state lead time: (a) in triangular fuzzy numbers; (b) in normal fuzzy numbers.

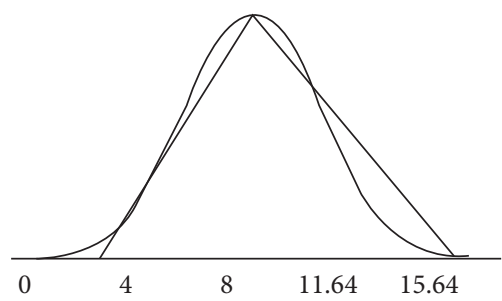

(a)

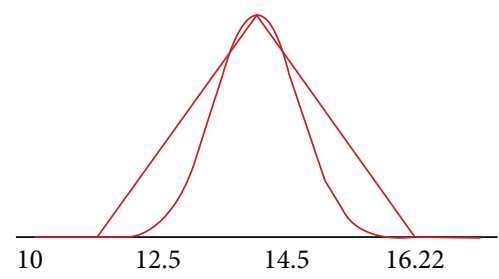

(b)

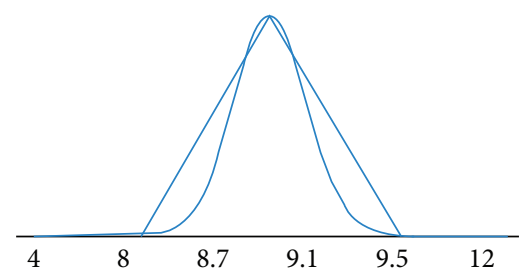

(c)

FIGURE 7: Lead time in triangular and normal fuzzy numbers: (a) current VSM (days); (b) future-state VSM $\mathrm{A}_{1}$ (hours); (c) future-state VSM $\mathrm{A}_{2}$ (hours).

superior to $\mathrm{VSM}_{1}$ in both TFN and NFN expressions. In conclusion, both the modified $\mathrm{CV}$ and centroid point methods identify future-state $\mathrm{VSM}_{2}$ as the ideal solution. It is worth noticing that, in this case, the comparison of the two alternative solutions is obvious because the membership functions of TFNs $\mathrm{A}_{1}$ and $\mathrm{A}_{2}$ make no interception, and the mean value and standard deviation of NTN $A_{2}$ are both lower than those of $A_{1}$.

\section{Discussion}

As demonstrated by the case study, the introduction of fuzzy logic to the traditional value stream analysis makes it possible to handle the variability and uncertainty of each step of the process, as well as the entire value stream. Both triangular and normal fuzzy membership functions incorporate variability in analysis and optimization. However, more consideration should be given to the choice between the two approaches (i.e., TFN and NFN).
The triangular and normal fuzzy expressions of the current state and two future states have been drawn in a single figure to compare the two approaches of the fuzzy expressions. As shown in Figure 7, the fuzzy TPLT of both the current state and future $\mathrm{A}_{1}$ solution presents different ranges of variations when the triangular and normal fuzzy expressions, respectively, are used. In contrast, $\mathrm{A}_{2}$ generates triangular and normal fuzzy TPLT expressions with similar lower and upper limits. The triangular fuzzy VSM appears to be less accurate in processes such as the current and $A_{1}$ states, which comprise more operational processes, as the addition of the individual lead time in each process amplifies the dispersion of the support of the triangular fuzzy TPLT. Therefore, a triangular fuzzy VSM tends to overestimate the variability of the process in a more complex productive environment (i.e., composed of more operational processes). However, a triangular fuzzy VSM permits a more accurate description of variation in the production environment, where the optimistic and pessimistic values have very different variations from the core. For example, in the current state VSM 


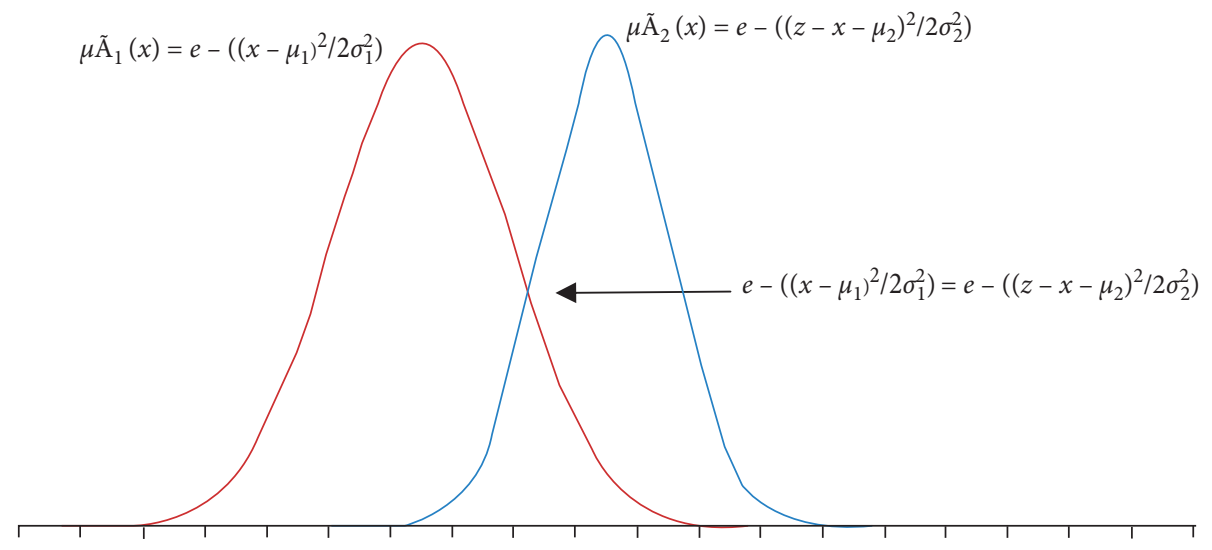

FIgURE 8: Functional images of $\tilde{\mathrm{A}}_{1}$ and $\tilde{\mathrm{A}}_{2}$.

(Figure 7(a)), the lopsidedness of the lower and upper limits of TPLT dispersed from the mean value could be manifested through the triangular fuzzy expression as a scalene triangle. However, the normal fuzzy VSM, in this case, appears to be less accurate for describing a symmetrical dispersion of TPLT.

\section{Conclusions}

In this study, fuzzy set theory was applied in VSM analysis to include variability in a manufacturing environment. The main idea behind fuzzy logic is to describe values using fuzzy numbers instead of deterministic values [11]. Two types of fuzzy numbers, TFN and NFN, were adopted to depict time intervals, inventories, and other operating variables in a value stream. An industrial application demonstrates the practicality and the effectiveness of the proposed fuzzy VSM for both TFN and NFN forms to incorporate variability in VSM analysis. Moreover, both triangular and normal fuzzy VSMs can be easily performed and applied, as only basic algebraic operations are required in the analysis and optimization process to ensure straightforward implementation in industrial cases. The choice between the two fuzzy number forms in VSM analysis is also discussed.

Accordingly, future research can be designed to avoid the disadvantages of the respective triangular and normal fuzzy VSM while retaining their advantages. For instance, TFN and NFN can be integrated to develop skeweddistributed fuzzy numbers to avoid overestimating the variability incurred by TFN addition on the one hand and illustrating the different variations of the optimistic and pessimistic estimates on the other hand. Additionally, the proposed fuzzy VSM optimization relies highly on the estimates of decision makers. Therefore, examining a fuzzy VSM through simulative approaches could be another interesting development for improving the accuracy of VSM analysis.

\section{Appendix}

\section{A. Proof Process of Equations (8) and (9)}

$$
\begin{aligned}
\widetilde{A}_{1}+\widetilde{A}_{2}(z) & =\bigvee_{x+y=z}\left(\widetilde{A}_{1}(x) \wedge \widetilde{A}_{2}(y)\right) \\
& =\bigvee_{x \in R}\left(\widetilde{A}_{1}(x) \wedge \widetilde{A}_{2}(z-x)\right) \\
& =\bigvee_{x \in R}\left(e^{-\left(\left(x-\mu_{1}\right)^{2} / 2 \sigma_{1}^{2}\right)} \wedge e^{-\left(\left(x-\mu_{2}\right)^{2} / 2 \sigma_{2}^{2}\right)}\right)
\end{aligned}
$$

rThe functional images of $\mu \tilde{\mathrm{A}}_{1}(x)=e^{-\left(\left(x-\mu_{1}\right)^{2} / 2 \sigma_{1}^{2}\right)}$ and $\mu \tilde{\mathrm{A}}_{2}(x)=e^{-\left(\left(z-x-\mu_{2}\right)^{2} / 2 \sigma_{2}^{2}\right)}$ are illustrated in Figure 8 .

$\vee_{x \in R}\left(e^{-\left(\left(x-\mu_{1}\right)^{2} / 2 \sigma_{1}^{2}\right)} \wedge e^{-\left(\left(x-\mu_{2}\right)^{2} / 2 \sigma_{2}^{2}\right)}\right)$ refers to the overlap of the two curves, and the intersection of the two functions is $e^{-\left(\left(x-\mu_{1}\right)^{2} / 2 \sigma_{1}^{2}\right)}=e^{-\left(\left(z-x-\mu_{2}\right)^{2} / 2 \sigma_{2}^{2}\right)}$.

Let

$$
\frac{\left(x-\mu_{1}\right)^{2}}{2 \sigma_{1}^{2}}=\frac{\left(z-x-\mu_{2}\right)^{2}}{2 \sigma_{2}^{2}}=d .
$$

Then,

$$
\begin{aligned}
\left(x-\mu_{1}\right)^{2} & =2 \sigma_{1}^{2} d, \\
\left(z-x-\mu_{2}\right)^{2} & =2 \sigma_{2}^{2} d, \\
\left(x-\mu_{1}\right)\left(z-x-\mu_{2}\right) & =2 \sigma_{1} \sigma_{2} d .
\end{aligned}
$$

Then,

$$
\begin{aligned}
\left(z-\mu_{1}-\mu_{2}\right)^{2}= & {\left[\left(x-\mu_{1}\right)+\left(z-x-\mu_{2}\right)\right]^{2} } \\
= & \left(x-\mu_{1}\right)^{2}+\left(z-x-\mu_{2}\right)^{2} \\
& +2\left(x-\mu_{1}\right)\left(z-x-\mu_{2}\right)=2 \sigma_{1}^{2} d+2 \sigma_{2}^{2} d+4 \sigma_{1} \sigma_{2} d \\
= & 2 d\left(\sigma_{1}+\sigma_{2}\right)^{2}
\end{aligned}
$$

Then, 


$$
d=\frac{\left(z-\mu_{1}-\mu_{2}\right)^{2}}{2\left(\sigma_{1}+\sigma_{2}\right)^{2}}
$$

Therefore,

$$
\underset{x \in R}{\vee}\left(e^{-\left(\left(x-\mu_{1}\right)^{2} / 2 \sigma_{1}^{2}\right)} \wedge e^{-\left(\left(x-\mu_{2}\right)^{2} / 2 \sigma_{2}^{2}\right)}\right)=e^{-\left(\left(z-\left(\mu_{1}+\mu_{2}\right)\right)^{2} / 2\left(\sigma_{1}+\sigma_{2}\right)^{2}\right)} .
$$

Similarly,

$$
\widetilde{A}_{1}-\widetilde{A}_{2}(z)=e^{-\left(\left(z-\left(\mu_{1}-\mu_{2}\right)\right)^{2} / 2\left(\sigma_{1}-\sigma_{2}\right)^{2}\right)} .
$$

\section{Data Availability}

The data used to support the findings of this study are included within this article.

\section{Conflicts of Interest}

The authors declare that there are no conflicts of interest regarding the publication of this paper.

\section{Acknowledgments}

This research was supported by the National Natural Science Foundation of China (NSFC) (grant no. 72071024).

\section{References}

[1] A. Susilawati, J. Tan, D. Bell, and M. Sarwar, "Fuzzy logic based method to measure degree of lean activity in manufacturing industry," Journal of Manufacturing Systems, vol. 34, pp. 1-11, 2015.

[2] T. L. Doolen and M. E. Hacker, "A review of lean assessment in organizations: an exploratory study of lean practices by electronics manufacturers," Journal of Manufacturing Systems, vol. 24, no. 1, pp. 55-67, 2005.

[3] T. Melton, "The benefits of lean manufacturing," Chemical Engineering Research and Design, vol. 83, no. 6, pp. 662-673, 2005.

[4] J. Slomp, J. A. C. Bokhorst, and R. Germs, "A lean production control system for high-variety/low-volume environments: a case study implementation," Production Planning \& Control, vol. 20, no. 7, pp. 586-595, 2009.

[5] B. Das, U. Venkatadri, and P. Pandey, "Applying lean manufacturing system to improving productivity of airconditioning coil manufacturing," The International Journal of Advanced Manufacturing Technology, vol. 71, no. 1-4, pp. 307-323, 2014.

[6] D. Seth and V. Gupta, "Application of value stream mapping for lean operations and cycle time reduction: an Indian case study," Production Planning \& Control, vol. 16, no. 1, pp. 44-59, 2005.

[7] S. J. Pavnaskar, J. K. Gershenson, and A. B. Jambekar, "Classification scheme for lean manufacturing tools," International Journal of Production Research, vol. 41, no. 13, pp. 3075-3090, 2003.

[8] A. Panwar, B. P. Nepal, R. Jain, and A. P. S. Rathore, "On the adoption of lean manufacturing principles in process industries," Production Planning \& Control, vol. 26, no. 7, pp. 564-587, 2015.
[9] S. Jing, Y. Tang, and J. Yan, "The application of fuzzy VIKOR for the design scheme selection in lean management," Mathematical Problems in Engineering, vol. 2018, Article ID 9253643, 15 pages, 2018.

[10] T. Itoh and H. Ishii, "Fuzzy due-date scheduling problem with fuzzy processing time," International Transactions in Operational Research, vol. 6, no. 6, pp. 639-647, 1999.

[11] M. Braglia, M. Frosolini, and F. Zammori, "Uncertainty in value stream mapping analysis," International Journal of Logistics Research and Applications, vol. 12, no. 6, pp. 435-453, 2009.

[12] W. J. Hopp and M. L. Spearman, Factory Physics, McGrawHill, New York, NY, USA, 2000.

[13] S. M. Seyedhosseini, A. E. Taleghani, A. Makui, and S. M. Ghoreyshi, "Fuzzy value stream mapping in multiple production streams: a case study in a parts manufacturing company," International Journal of Management Science and Engineering Management, vol. 8, no. 1, pp. 56-66, 2013.

[14] C. E. Pérez-Pucheta, E. Olivares-Benitez, H. Minor-Popocatl, P. F. Pacheco-García, and M. F. Pérez-Pucheta, "Implementation of lean manufacturing to reduce the delivery time of a replacement part to dealers: a case study," Applied Sciences, vol. 9, no. 18, pp. 3932-3954, 2019.

[15] R. Acero, M. Torralba, R. Pérez-Moya, and J. A. Pozo, "Value stream analysis in military logistics: the improvement in order processing procedure," Applied Sciences, vol. 10, no. 1, 106 pages, 2020.

[16] E. Alzubi, A. M. Atieh, K. Abu Shgair et al., "Hybrid integrations of value stream mapping, theory of constraints and simulation: application to wooden furniture industry," Processes, vol. 7, no. 11, pp. 819-833, 2019.

[17] P. F. Andrade, V. G. Pereira, and E. G. Del Conte, "Value stream mapping and lean simulation: a case study in automotive company," The International Journal of Advanced Manufacturing Technology, vol. 85, no. 1-4, pp. 547-555, 2016.

[18] R. Álvarez, R. Calvo, M. M. Pena, and R. Domingo, "Redesigning an assembly line through lean manufacturing tools," The International Journal of Advanced Manufacturing Technology, vol. 43, no. 9-10, pp. 949-958, 2009.

[19] D. Tapping, T. Luyster, and T. Shuker, Value Stream Management, Productivity Press, NewYork, NY, USA, 2002.

[20] L. Parv, B. Deaky, M. Nasulea, and G. Oancea, "Agent-based simulation of value flow in an industrial production process," Processes, vol. 7, no. 2, pp. 82-96, 2019.

[21] M. Rother and J. Shook, Learning to See-Value Stream Mapping to Add Value and Eliminate Muda, The Lean Enterprise Institute, Cambridge, MA, USA, 1998.

[22] I. Serrano, C. Ochoa, and R. D. Castro, "Evaluation of value stream mapping in manufacturing system redesign," International Journal of Production Research, vol. 46, no. 16, pp. 4409-4430, 2008.

[23] Z. Abbas, N. Khaswala, and S. Irani, "Value network mapping (VNM): visualization and analysis of multiple flows in value stream maps," in Proceedings of the Lean Management Solutions Conference, St Louis, MO, USA, 2001.

[24] M. Braglia, G. Carmignani, and F. Zammori, "A new value stream mapping approach for complex production systems," International Journal of Production Research, vol. 44, no. 1819, pp. 3929-3952, 2006.

[25] T. McDonald, E. M. Van Aken, and A. F. Rentes, "Utilising simulation to enhance value stream mapping: a manufacturing case application," International Journal of Logistics Research and Applications, vol. 5, no. 2, pp. 213-232, 2002. 
[26] Y.-H. Lian and H. V. Landeghem, "An application of simulation and value stream mapping in lean manufacturing," in Proceedings of the 14th European Simulation Symposium, SCS Europe BVBA, Dresden, Germany, 2002.

[27] S. J. Pavnaskar and J. K. Gershenson, "The application of value stream mapping to lean engineering," in Proceedings of the 2004 International Design Engineering Technical Conferences and Computers and Information in Engineering Conference, ASME, Salt Lake City, UT, USA, October 2004.

[28] K. Zokaei and D. Simons, "Performance improvements through implementation of lean practices: a study of the U.K. Red meat industry," International Food and Agribusiness Management Association, vol. 9, no. 2, pp. 30-53, 2006.

[29] E. Jiménez, A. Tejeda, M. Pérez, J. Blanco, and E. Martínez, "Applicability of lean production with VSM to the Rioja wine sector," International Journal of Production Research, vol. 50, no. 7, pp. 1890-1904, 2012.

[30] B. V. Chowdary and D. George, "Improvement of manufacturing operations at a pharmaceutical company: a lean manufacturing approach," Journal of Manufacturing Technology Management, vol. 23, no. 1, pp. 56-75, 2012.

[31] R. Jafari and W. Yu, "Fuzzy modeling for uncertainty nonlinear systems with fuzzy equations," Mathematical Problems in Engineering.vol. 2017, Article ID 8594738, 10 pages, 2017.

[32] L. Abdullah and F. N. Azman, "Circumcenter of centroid of fuzzy number for identifying risk factors of obesity: a qualitative evaluation," Quality \& Quantity, vol. 50, no. 6, pp. 2433-2449, 2016.

[33] L. A. Zadeh, "Fuzzy sets," Information and Control, vol. 8, no. 3, pp. 338-353, 1965.

[34] H. Rommelfanger, "FULPAL: an interactive method for solving (multiobjective) fuzzy linear programming problems," in Stochastic versus Fuzzy Approaches to Multiobjective Mathematical Programming under Uncertainty, R. Slowinski and J. Teghem, Eds., pp. 279-299, Kluwer Academic Publishers, Dordrecht, Netherlands, 1990.

[35] C.-H. Cheng, "A new approach for ranking fuzzy numbers by distance method," Fuzzy Sets and Systems, vol. 95, no. 3, pp. 307-317, 1998.

[36] E. S. Lee and R.-J. Li, "Comparison of fuzzy numbers based on the probability measure of fuzzy events," Computers \& Mathematics with Applications, vol. 15, no. 10, pp. 887-896, 1988.

[37] T.-C. Chu and C.-T. Tsao, "Ranking fuzzy numbers with an area between the centroid point and original point," Computers \& Mathematics with Applications, vol. 43, no. 1-2, pp. 111-117, 2002.

[38] Y.-M. Wang, J.-B. Yang, D.-L. Xu, and K.-S. Chin, "On the centroids of fuzzy numbers," Fuzzy Sets and Systems, vol. 157, no. 7, pp. 919-926, 2006. 